\title{
SIMULATIONS OF WATER CYCLE IN THE SOIL-CROP SYSTEM: MODEL IMPROVEMENT AND VALIDATION
}

\author{
ZHANG, K. F. ${ }^{1}-$ LI, C. ${ }^{1}-$ HU, Z. F. ${ }^{2 *}-$ HuANG, S. Q. ${ }^{1}-$ CHEN, J. S. ${ }^{3}-$ MA, X. F. ${ }^{3}$ \\ ${ }^{1}$ Ningbo Institute of Technology, Zhejiang University, Ningbo 315100, China \\ (phone: +86-574-8813-0254; fax: +86-574-8813-0283) \\ ${ }^{2}$ Design and Research Institute of Environmental Protection Sciences of Zhejiang Province, \\ Hangzhou 310007, China \\ ${ }^{3}$ Ningbo Haitong Times Agricultural Co. Ltd, Cixi, Zhejiang Provice, China \\ *Corresponding author \\ e-mail: huzhengfeng2003@outlook.com
}

(Received $15^{\text {th }}$ Sep 2019; accepted $8^{\text {th }}$ Jan 2020)

\begin{abstract}
Accurate estimation of soil water dynamics, soil evaporation and crop transpiration are of great importance to make the best use of water in agriculture. In this study, the EU-Rotate_N model, which had been widely used for water and nitrogen dynamics for vegetables crops, was improved and evaluated for its capacity of simulating soil water movement under the condition of relatively high groundwater table. Rigorous validation of the newly modified model against data from two experiments on lettuce and tomato revealed that the simulated values of soil water content at various depths during crop growth were much better than those computed with the original model, compared with the measured values. The calculated statistical indices of the Nash-Sutcliffe model efficiency coefficient and the model agreement index were 0.556 and 0.808 , respectively, for the Lettuce experiment, while the corresponding figures were 0.750 and 0.938 for the Tomato experiment. This indicates that the improvement of EU-Rotate_N model was a success, and the modified model could be used in crop production for water and nitrogen management more widely. Finally, the further improvement of the model to enhance its accuracy of predicting soil water dynamics was discussed.
\end{abstract}

Keywords: soil water dynamics, EU-Rotate_N model, agricultural water management, SPAC system, agro-hydrological modelling

\section{Introduction}

Soil moisture is a key variable for understanding hydrological process in the vadose zone. Agricultural and irrigation management practices largely depend on a timely and accurate characterization of temporal and spatial soil moisture dynamics in the root zone because of the impact of soil moisture on the production and health status of crops and salinization (Vereecken et al., 2008; Greenwood et al., 2010; Dogan et al., 2019). Additionally, soil moisture also plays a major role in the organization of natural ecosystems and biodiversity.

Mathematical models are powerful tools to estimate water and nutrients requirement of crops, which is essential information required to devise best farming practices in agriculture. The simulations of agricultural systems for water and nutrient cycles have increased drastically over the last two decades, in line with the development of more powerful hardware and software, and use-friendly interfaces, see reviews by Cannavo et al. (2008) and Kumar et al. (2013). Accurate modeling of water movement is crucially important for agro-hydrological models. Numerous studies on simulating water movement in the soil-crop system have been proposed for various crops grown under 
diverse conditions (Ahuja et al., 1993; Brisson et al., 1998; Shaffer and Brodahl, 1998; Šimunek et al., 1999; Rahn et al., 2010; Zhang et al., 2010; Sun et al., 2012; Kumar et al., 2013; Sun et al., 2013; Wang et al., 2013; Mohammad et al., 2014; Karandish and Šimůnek, 2018; Landl et al., 2019). Amongst these models, there were two approaches in simulating water dynamics in the soil. On the one hand, the mechanistic models described the movement of water in the soil by the Darcy's law, and the basic flow equation was solved numerically, as shown in RZQM (Ahuja et al., 1993) and Hydrus2D (Šimunek et al., 1999) models. On the other hand, empirical approaches were used for soil water movement in agro-hydrological models such as STICS (Brisson et al., 1998), NLEAP (Shaffer and Brodahl, 1998), N_ABLE (Greenwood, 2001) and EURotate_N (Rahn et al., 2010) models. In the empirical approaches the soil was divided into several layers, each with a specific water storage capacity according to the soil texture or its physical properties. Water entering a particular soil layer was stored until the moisture level reached field capacity, with water above this limit draining to the lower adjacent layer, at a rate varying among models. Soil water content at field capacity played a determinant role in the transport of water in the empirical approaches.

Since the algorithms used in the empirical approaches are fairly simple and parameters are relatively limited and easily available, empirical approaches are still widely used in agro-hydrological models for predicting soil water movement (Greenwood, 2001; Zhang et al., 2007, 2009; Pedersen et al., 2010). The EU-Rotate_N model (Rahn et al., 2010), which was developed recently with a similar approach for soil water movement, has shown encouraging results in simulating various crops on different sites under diverse climate conditions (Doltra and Muñoz, 2010; Guo et al., 2010; Rahn et al., 2010; Sun et al., 2013; Soto et al., 2014). Guo et al. (2010) concluded that the EU-Rotate_N model, which was initially designed for the use in European outdoor field conditions, could be applied in typical greenhouse in China without major modifications. Sun et al. (2013) calibrated and validated the EU-Rotate_N model for greenhouse tomato, and found the simulated values of soil water content were in good agreement with measured data. Similar results were also reported in the study by Soto et al. (2014). However, the experiments in the above studies on different crops were conducted under the condition of low groundwater table as the EU-Rotate_N model was originally designed for, and no reports were available on the accuracy of the simulated soil water content for crops grown under the relatively high groundwater table.

The main purposes of this study were twofold: (1) to modify the algorithm for soil water movement in the EU-Rotate_N model to enable it for crops grown under different groundwater conditions, and (2) to evaluate the modified model against data from two field experiments on lettuce and tomato conducted under relatively high groundwater condition.

\section{Materials and methods}

\section{Improvements of the $E U$-Rotate_N model}

EU-Rotate_N model was originally designed for simulating water and nitrogen dynamics in the soil-crop system for crop rotations (Rahn et al., 2010). The modules for crop growth and nitrogen requirement were identical with those in N_ABLE (Greenwood, 2001), which was well validated over a wide range of crops. The modules for soil water movement were newly developed. A cascade approach for soil water flow was employed. The algorithm for such an approach was simple, but did not work well 
universally. For the situations of relatively high groundwater table, modification of the algorithm is essentially required.

In the original EU-Rotate_N model, the soil was divided into $5 \mathrm{~cm}$ layers, and a capacity-based algorithm was used to calculate downwards water movement between soil layers (Rahn et al., 2010). In this approach, at any layer, the excessive water above field capacity $\left(\theta_{F C}\right)$ drained to the layer below, provided that the soil in that layer was not saturated. The amount of water that drains on a given day, $D r_{i}(\mathrm{~mm})$, was limited by a drainage coefficient, $C_{d r}$, which accounted for the effect of the soil hydraulic conductivity (Doltra and Muñoz, 2010), i.e.:

$$
D r_{i}= \begin{cases}C_{d r}\left(\theta_{i}-\theta_{F C i}\right) T_{i} & \theta_{i}>\theta_{F C i} \\ 0 & \text { otherwise }\end{cases}
$$

where $\theta_{i}\left(\mathrm{~cm}^{3} \mathrm{~cm}^{-3}\right)$ represents soil water content of the layer $i, \theta_{F C i}\left(\mathrm{~cm}^{3} \mathrm{~cm}^{-3}\right)$ is the water content at field capacity, and $T_{i}(\mathrm{~mm})$ is the thickness of the soil layer. The drainage coefficient $C_{d r}$ is calculated using the following equation:

$$
C_{d r i}=\left(\theta_{s i}-\theta_{F C i}\right) / \theta_{s i}
$$

in which $\theta_{s i}\left(\mathrm{~cm}^{3} \mathrm{~cm}^{-3}\right)$ is the soil water content at saturation in the layer $i$.

It has been demonstrated that the above algorithm performed well in predicting soil water content under the condition of deep groundwater table (Wang et al., 2013; Doltra and Muñoz, 2010; Guo et al., 2010; Soto et al., 2014). However, when the groundwater table is relatively high, drainage may not occur in some part of the computational domain. Also, in the event of soil water content in a layer is smaller than that in the layer below for a given soil, no drainage would happen either. Therefore, in order for the model to deal with such situations, alterations of the algorithm for soil water movement of the model are required. In this study, we proposed the following algorithm for computing soil water drainage. The total amount of water drainage between soil layers, for a given soil layer $i$, was assumed to be the sum of the excessive water above saturation, $D r_{i l}$, and the drained water induced by soil water content between field capacity and saturation, $D r_{i 2}$, i.e.

$$
D r_{i}=D r_{i 1}+D r_{i 2}
$$

where $D r_{i 1}(\mathrm{~mm})$ is the excessive water above saturation, $D r_{i 2}$ is the drainage amount caused by soil water above field capacity.

$$
D r_{i 1}= \begin{cases}\left(D r_{i-1} / T_{i}+\theta_{i}-\theta_{s i}\right) T_{i} & D r_{i-1} / T_{i}+\theta_{i}-\theta_{s i}>0 \\ 0 & \text { otherwise }\end{cases}
$$

where $D r_{i-1}(\mathrm{~mm})$ is the drainage amount from the soil layer above $i-1$.

The equation for calculating $D r_{i 2}(\mathrm{~mm})$ is given below: 


$$
D r_{i 2}= \begin{cases}C_{d r}\left(\theta_{s i}-\theta_{F C i}\right) T_{i} & D r_{i 1}>0 \\ C_{d r}\left(D r_{i-1} / T_{i}+\theta_{i}-\theta_{F C}\right) T_{i} & D r_{i-1} / T_{i}+\theta_{i}>\theta_{F C_{i}} \text { and } \theta_{i}+D r_{i-1} / T_{i}>\theta_{i+1} \text { (Eq.5) } \\ 0 & \text { otherwise }\end{cases}
$$

where $\theta_{i+1}$ is the soil water content in the layer below $i+1$.

\section{Experiments}

The experiments on lettuce (Lactuca sativa L.) and tomato (S. lycopersicum) were carried out on the farm of Haitong Times Agricultural Co Ltd, Cixi, Ningbo, Zhejiang province, in eastern China $\left(121.50^{\circ} \mathrm{E}, 30.11^{\circ} \mathrm{N}\right)$. The location is $7 \mathrm{~km}$ away from the seaside. The soil in the farm is silty loam, with fairly uniform distribution in the profile. The soil physical properties are shown in Table 1.

Table 1. Soil physical properties in the experimental site

\begin{tabular}{c|c|c|c|c|c}
\hline Soil layer (cm) & Texture (-) & Sand (\%) & Silt (\%) & Clay (\%) & Bulk density $\left(\mathbf{g ~ c m}^{-3}\right)$ \\
\hline $0-20$ & Silty loam & 48.5 & 46.8 & 4.7 & 1.19 \\
$>20$ & Silty loam & 49.1 & 46.5 & 4.4 & 1.45 \\
\hline
\end{tabular}

A fully randomized method was used in the experimental design. The field was divided into 7 experimental plots. The plots for the Tomato experiment were $6 \mathrm{~m} \times$ $30 \mathrm{~m}$, and the size for the Lettuce experiment was $6 \mathrm{~m} \times 10 \mathrm{~m}$. Lettuce was sowed on 3 June 2014 and harvested on 31 July 2014, while tomato was transplanted on 23 April 2014 and harvested on 15 August 2014. Lettuce was broadcast sowed, having an averaged plant population of 70 plants $\mathrm{m}^{-2}$. Tomato plants were spaced at $30 \mathrm{~cm}$ within the row and $60 \mathrm{~cm}$ between rows. No irrigation was applied during the experiments, except for a small amount of irrigation in the seedling stage to help plants to develop. Fertiliser management was in accordance with local farming practice which was used for growing the same crops in the farm over the years. Pests control was carried out by conventional pesticides, when it was required. Weeds were managed manually.

Soil volumetric water content was measured with the SM100 sensors (Spectrum Technologies, Inc., Aurora, IL, USA). The SM100 sensors were positioned at the 10, $30,50 \mathrm{~cm}$ depths in both the Lettuce and the Tomato experiments (unfortunately the sensors at the $30 \mathrm{~cm}$ depth did not function properly in the Tomato experiment). Since the measurements of soil water content in the soil profile were used for testing the model, it was not necessary to collect data from the depths too close to each other. The selection of soil depths with $20 \mathrm{~cm}$ intervals for sensors in this study was according to common practice for similar crop experiments. Sensors were installed in the soil horizontally. Prior to the installations, the SM100 sensors were calibrated using soil pillars with difference water content in the lab according to the product's manual. The volumetric water content data were recorded every $30 \mathrm{~min}$ on a Watchdog 1400 data logger (Spectrum Technologies, Inc., Aurora, IL, USA).

Daily air temperature and relative humidity were provided by a local weather station. Solar radiation was automatically measured and recorded every $30 \mathrm{~min}$ with a pyranometer (Mod. TBQ-2, JinZhou Sunshine Meteorological Science Co., Liaoning, China). Since the model uses a daily time step, the frequency of every $30 \mathrm{~min}$ for 
collecting solar radiation was considered sufficient enough. Rainfall was measured and recorded by Watchdog Data-Logging Rain Gauge (Spectrum Technologies, Inc.). Both solar radiation and rainfall were collected at the weather station installed on the experimental site. The observation of groundwater table was carried out in a well which was dig in the experimental field. The measured values of daily mean air temperature, relative humidity, rainfall and solar radiation are shown in Figure 1.



(a)

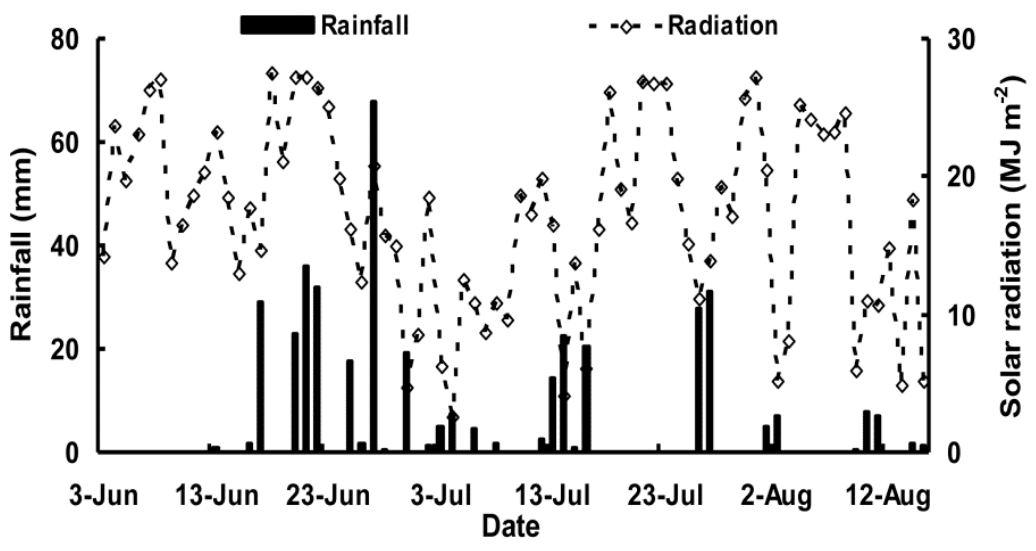

(b)

Figure 1. Measured daily mean air temperature and relative humidity (a), solar radiation and rainfall (b) during the experiments

\section{Preparation of model run}

\section{Model parameterization}

The parameters required to run the modified EU-Rotate_N model were the same as those for the original model listed in Rahn et al. (2010). Basically, the data from soil, crop and weather were required in the simulations. In this study, the model was used for modeling water dynamics in the soil-crop system, and therefore the data given below were only for this purpose. 
The required soil data were fairly simple and limited, including characteristic soil water content at saturation, field capacity and the permanent wilting point. Such a dataset was obtained by applying the Saxton and Rawles' (2006) approach to the measured soil physical properties. Saxton and Rawles' (2006) proposed a set of pedotransfer functions for estimating characteristic soil water content and soil moisturetension relationships for various types of soils. The derived equations were based on soil texture and soil particle distribution (Saxton et al., 1986), and have been used extensively in previous studies for determining characteristic soil water content and soil hydraulic functions (Fry et al., 2014; Nyeko, 2015).

Crop data used in the EU-Rotate_N model were the dates of crop planting/sowing and harvest, and the durations of the various crop growth stages and their associated dual coefficients for potential soil evaporation and crop transpiration. The durations of the initial, development, middle and late stages for the crop were calculated according to the proportionalities over the entire growth period given in the FAO56 (Allen et al., 1998) for a given crop. Also, the corresponding values of crop coefficient were taken from the FAO56. Thus, on any day during growth the values of potential evaporation and transpiration could be calculated, given the reference evapotranspiration ETo was known. The detailed procedure for calculating ETo was given elsewhere (Allen et al., 1998).

Weather data were mainly used for estimating daily ETo. The weather variables, including daily air temperature, relative humidity, solar radiation, wind speed and rainfall, were all measured in the way described above, and were used directly in the simulations.

\section{Computational domain and boundary conditions}

The calculated soil depth in the EU-Rotate_N model was fixed to $200 \mathrm{~cm}$ (Rahn et al., 2010, 2007). The soil column was evenly divided into 40 layers with a thickness of $5 \mathrm{~cm}$ each layer. The model operated on a daily basis. The upper boundary condition in both experiments was set as atmospheric, i.e. the top soil layer subject to rainfall and evaporation. The lower boundary was specified as the soil below the $70 \mathrm{~cm}$ depth in saturation based on the observations. The time of the first measurements and the measured values of soil water content along the profile were used as the starting point and the initial conditions of the simulations.

\section{Model evaluation}

To evaluate the ability of the modified model to predict the values of temporal and spatial soil water content, statistical analyses were carried out using the indices of the Nash-Sutcliffe model efficiency coefficient (NSE) (Nash and Sutcliffe, 1970), the root of the mean squared errors (RMSE) and the model agreement index $(d)$ (Willmott, 1981). These indices were used extensively in assessing hydrological models in previous studies.

$$
N S E=1-\frac{\sum_{i=1}^{n}\left(Y-Y^{\prime}\right)^{2}}{\sum_{i=1}^{n}\left(Y-\overline{Y^{\prime}}\right)^{2}}
$$




$$
\begin{gathered}
d=1-\frac{\sum_{i=1}^{n}\left(Y-Y^{\prime}\right)^{2}}{\sum_{i=1}^{n}\left(\left|Y-\overline{Y^{\prime}}\right|+\left|Y^{\prime}-\overline{Y^{\prime}}\right|\right)^{2}} \\
R M S E=\sqrt{\frac{1}{n} \sum_{i=1}^{n}\left(Y-Y^{\prime}\right)^{2}}
\end{gathered}
$$

where $n$ is the total number of samples, $Y$ and $Y^{\prime}$ are the simulated and measured values, respectively, and $\overline{Y^{\prime}}$ is the average of the measured values. For a perfect match between simulation and measurement, both NSE and $d$ are equal to 1 , and RMSE is 0 .

\section{Results and discussion}

For the evaluation of the modified model, both the original and modified models were first run against the same measured data collected from the experiments on lettuce and tomato. The simulated results were then compared to make an objective assessment of the performance of the modified model.

\section{Overall evaluation of the modified model}

The overall comparison of temporal and spatial soil water content between simulation and measurement for both Lettuce and Tomato experiments is shown in Figure 2, and the quantitative statistical results are listed in Table 2. In both experiments, the simulated values are highly correlated with the measured values (Fig. 2). The gradient of the best fitted lines is approximately 1 and the intercept is close to 0 . The regressions of the simulated values against the measured values give a high $\mathrm{R}^{2}$ value greater than 0.61 . The calculated values of $N S F$ and $d$ are greater than 0.56 and 0.81 , respectively, while the $R M S E$ value is smaller than $0.027 \mathrm{~cm}^{3} \mathrm{~cm}^{-3}$. The calculation of $N S F, d$ and $R M S E$ values were also carried out for the simulated results from the original model. The calculated RMSE were 0.038 and $0.036 \mathrm{~cm}^{3} \mathrm{~cm}^{-3}$ for lettuce and tomato, respectively, greater than those from the modified model (Table 2). The values of NSF were -1.838 for lettuce and 0.562 for tomato, much worse than those from the modified model. This was especially true for the Lettuce experiment where $N S F$ value even went to negative, indicating that the original model was unable to make reasonable predictions. All these indices suggest that the original model performed poorly and the modified EU-Rotate_N model was capable of re-producing measurements of soil water content fairly well. This proves that the improvement of the model was essential and successful.

Detailed comparisons of soil water content between the measured and simulated values with the modified EU-Rotate_N model at various depths in both experiments during crop growth were carried out (Figs. 3 and 4). Also shown in the graphs were the simulated results of soil water content from the original EU-Rotate_N model. It is evident that the simulated results from the modified model were far better than those from the original model, compared with the measured values. Not only did the modified model produce the same variation patterns in soil water content, but also the values were in good agreement with the measurements throughout the growing periods. The 
original model, on the other hand, failed to produce the results comparable with the measurements. The discrepancies between the measurement and simulation with the original model increased with time, especially at the deeper depths. The principal reasons for the discrepancies were due to the inability of the original model to handle the lower boundary condition of soil at saturation and the inappropriate algorithm for downwards water flow between soil layers. Clearly, Figs. 3 and 4 demonstrated that the modification of the model was essential to simulate the crops in the present experiments. The work carried out in this study was a significant improvement of the original model to extend its use for modeling water dynamics in the soil-crop system under more diverse conditions.

Table 2. Statistical indices of the simulated results of soil water content

\begin{tabular}{c|c|c|c}
\hline Experiment & $\boldsymbol{R M S E}\left(\mathbf{c m}^{\mathbf{3}} \mathbf{c m}^{\mathbf{- 3}}\right)$ & $\boldsymbol{N S E} \mathbf{( - )}$ & $\boldsymbol{d}(-)$ \\
\hline Lettuce & 0.024 & 0.556 & 0.808 \\
Tomato & 0.027 & 0.750 & 0.938 \\
\hline
\end{tabular}

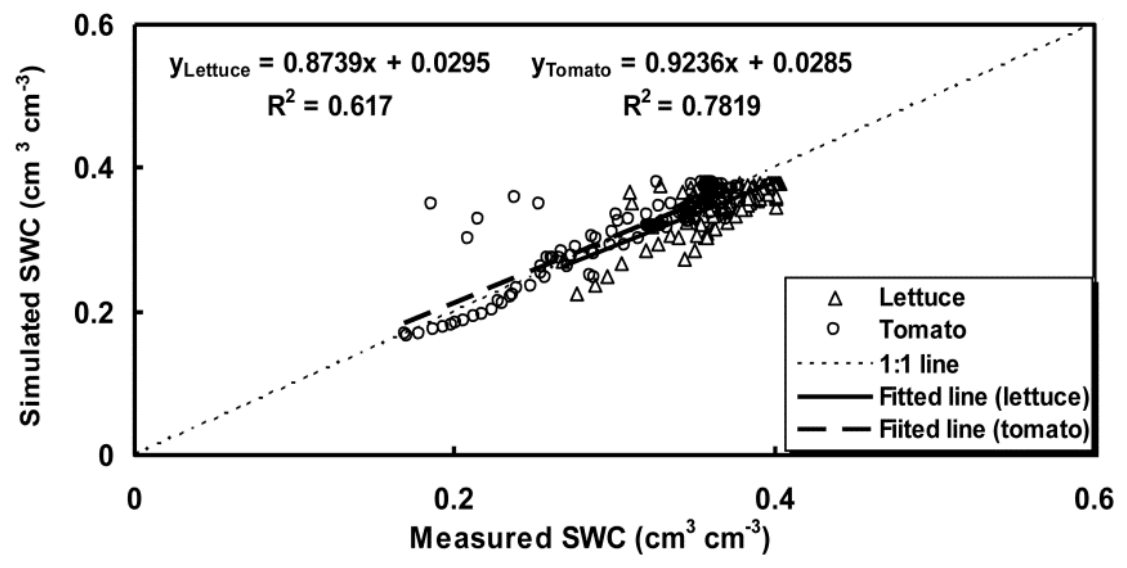

Figure 2. Overall comparison of soil water content ( $S W C)$ between simulation and measurement.

In the Lettuce experiment soil water content remained high and fairly constant at the $30 \mathrm{~cm}$ and $50 \mathrm{~cm}$ depth, except for the beginning and towards the end of the experiment (Fig. 3). This could be attributed to the fact that during the most period of the experiment the amount of rainwater exceeded the crop evapotranspirational demand. Over the experiment the cumulative rainfall reached as high as $367.6 \mathrm{~mm}$. At the $50 \mathrm{~cm}$ depth, the soil was near its saturation throughout the experiment caused by combined effects of excessive rainfall, high groundwater table and the short rooting depth of the crop. Marked changes in soil water content at the $10 \mathrm{~cm}$ depth were observed and simulated in the Tomato experiment (Fig. 4). Soil water content decreased steadily at the beginning of the experiment due to the dry spell during the period. Big increase in soil water content occurred during the heavy rain period between $16^{\text {th }}$ June to $30^{\text {th }}$ June when an increase of $0.18 \mathrm{~cm}^{3} \mathrm{~cm}^{-3}$ was recorded and $0.19 \mathrm{~cm}^{3} \mathrm{~cm}^{-3}$ was simulated. High and fairly constant soil water content during $1^{\text {st }}$ July to $10^{\text {th }}$ July was observed for the reason explained in the Lettuce experiment. At the later stages of the experiment there 
were 3 dry-wet cycles which coincided with the rain pattern (Fig. 1). The changes in simulated soil water content at the $50 \mathrm{~cm}$ depth were small, in good agreement with the measurements (Fig. 4).

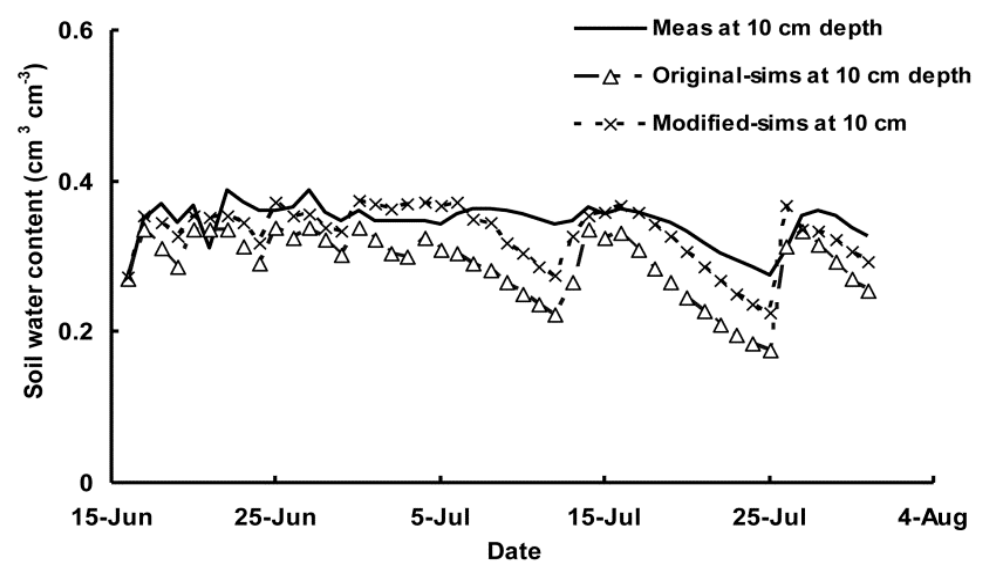

(a)

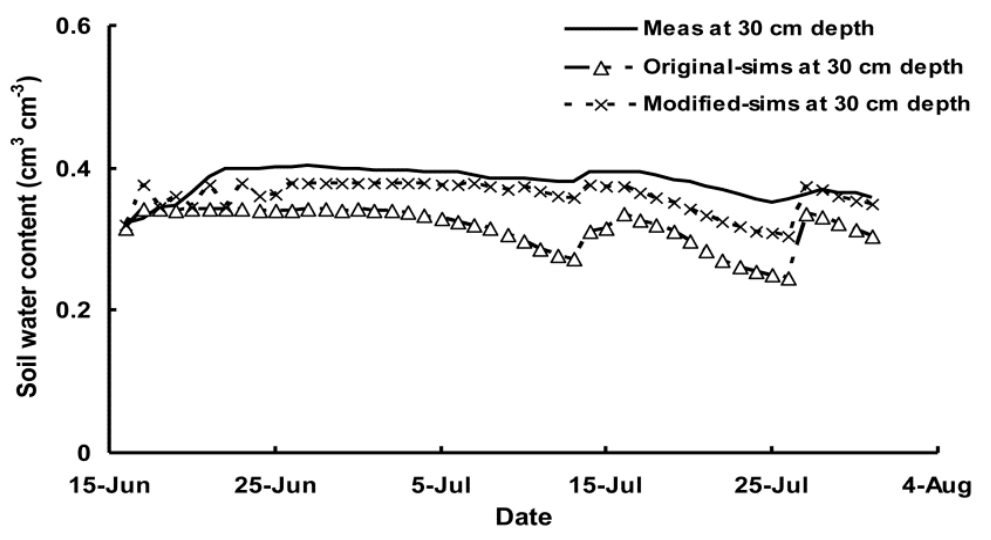

(b)

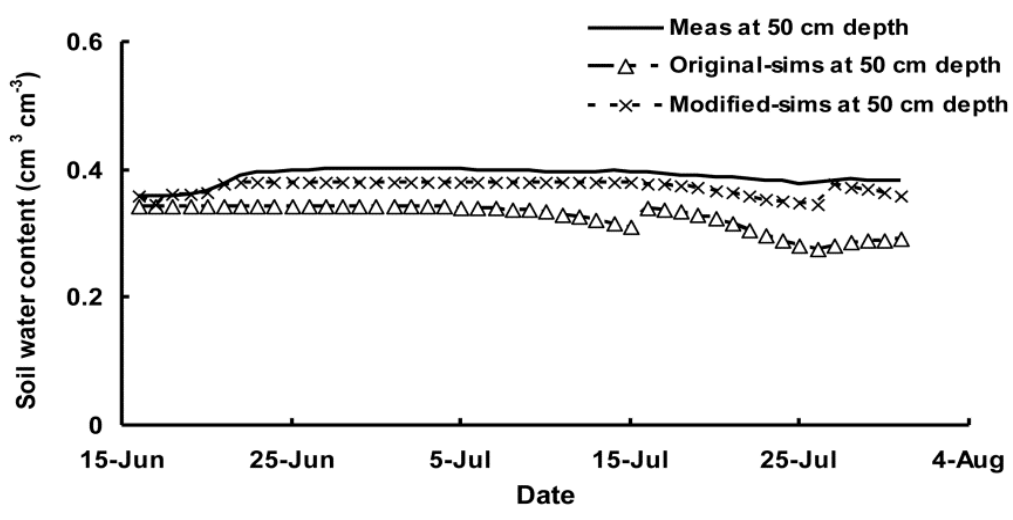

(c)

Figure 3. Detailed comparison soil water content at the depths of $10 \mathrm{~cm}(\mathrm{a}), 30 \mathrm{~cm}(\mathrm{~b})$ and $50 \mathrm{~cm}(\mathrm{c})$ between simulation and measurement in the Lettuce experiment 


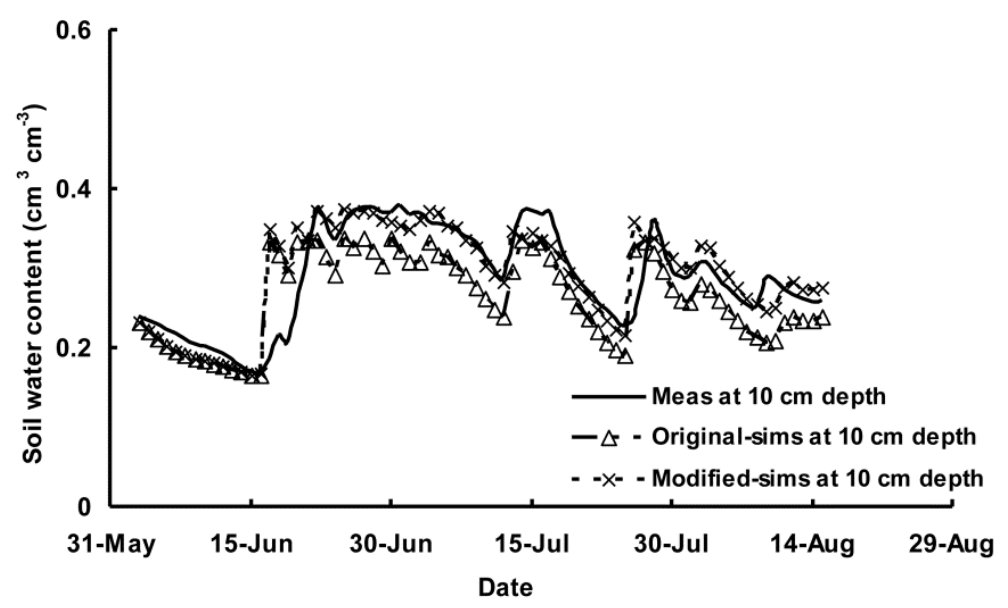

(a)



(b)

Figure 4. Detailed comparison soil water content at the depths of $10 \mathrm{~cm}(\mathrm{a})$ and $50 \mathrm{~cm}(\mathrm{~b})$ between simulation and measurement in the Tomato experiment

\section{The simulated soil evaporation and crop transpiration}

Figure 5 shows the cumulative simulated soil evaporation and crop transpiration during growth, together with the cumulative rainfall. In both experiments, the simulated seasonal evapotranspiration approximately equaled the potential value, suggesting that the crop demand for water for the maximum growth was basically met. This was primarily down to the fact that the experiments were carried out in the fairly wet season. The cumulative seasonal potential evapotranspiration were $188.8 \mathrm{~mm}$ and $251.8 \mathrm{~mm}$ for the Lettuce and Tomato experiments, respectively, far less than the cumulative rainfall of $367.6 \mathrm{~mm}$ and $398.5 \mathrm{~mm}$ in the same periods. This indicates that the crop evapotranspiration was mainly met by the rainfall, not so much by the initially stored soil water. High soil evaporation occurred at the early crop development stage (Fig. 5). At this stage the ground cover was less intense and thus the evaporation demand was larger. Contrary to soil evaporation, the big crop transpiration happened when the crop 
was at its mid-season and later development stage. It should be pointed out that due to the combined effects of lack of rainfall (Fig. 1b) and the dry soil on the surface (Fig. 4a), soil evaporation was neglectable before $16^{\text {th }}$ June in the Tomato experiment even when the crop was small (Fig. $5 b$ ).

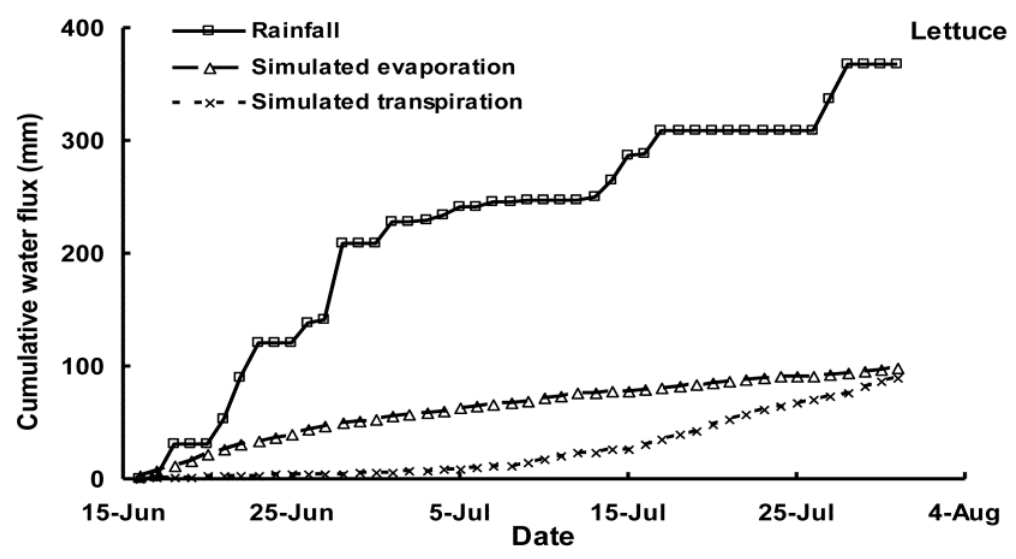

(a)

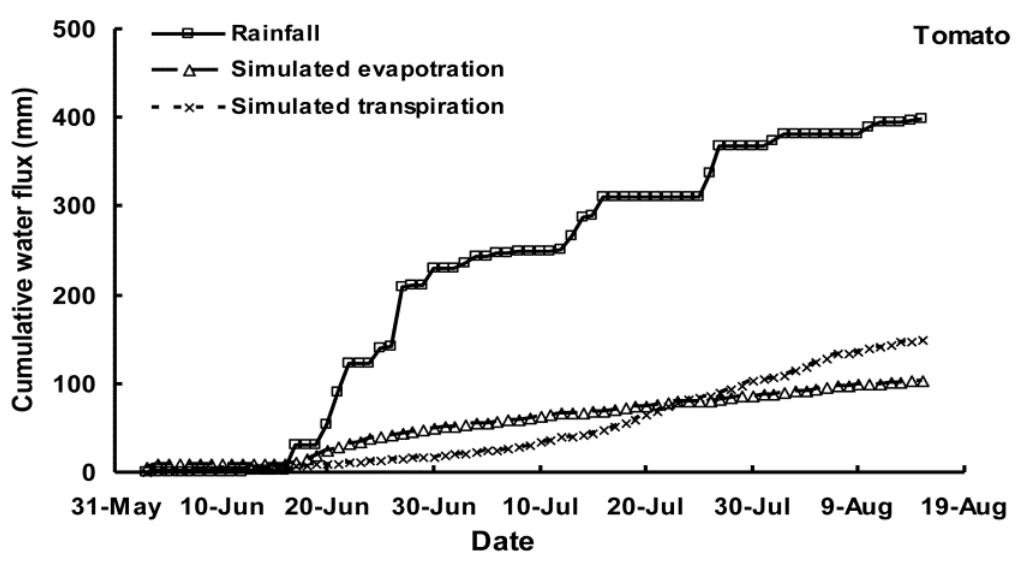

(b)

Figure 5. Cumulative rainfall, simulated evaporation and transpiration in the Lettuce experiment (a) and in the Tomato experiment (b)

\section{Crop water uptake from the rooting depth}

It is interesting to quantify the proportions of crop transpiration made by roots in various part of the rooting depth. There have been reports that each quarter of the rooting depth from the surface accounted for about $40 \%, 30 \%, 20 \%$ and $10 \%$ of the total water uptake (Molz and Remson, 1970; Kumar et al., 2013). In both experiments in this study the potential crop transpiration was all basically met (Fig. 5), indicating that roots in the various parts of the root zone absorbed the assigned amount of potential transpiration. Since the assignment of potential transpiration was according to the root distribution in the soil profile, the proportion of water uptake in each rooting depth was equal to that of the root distribution. In the EU-Rotate_N model, root distribution was 
normalized in the soil in the manner of $\int_{0}^{1} e^{-\alpha z} d z$ with $\alpha$ being the shape parameter controlling root distribution, $\mathrm{z}$ being 0 at the surface and 1 at the bottom of the root zone (Rahn et al., 2010). $\alpha$ was parameterized to be 2 for both lettuce and tomato in the model. This worked out that each quarter of rooting depth from the upmost contributed about $46 \%, 28 \%, 17 \%$ and $10 \%$ of the total water uptake, respectively, in agreement with the experimental evidence by Molz and Remson (1970) and Kumar et al. (2013). The EU-Rotate_N model is a generic model for water and nitrogen management in crop production, and has up-to-data been parameterized for a wide range of crops (Rahn et al., 2010). For all the crops in the model the shape parameter $\alpha$ varies from 1.5 to 3 . Table 3 shows the proportions of roots in each quarter of the normalized rooting depth calculated from different shape parameter values. Broadly they are in reasonable ranges.

Table 3. Proportion of roots in each quarter of the normalised rooting depth

\begin{tabular}{c|c|c|c|c}
\hline $\boldsymbol{\alpha}^{\mathbf{a}}$ & $(\mathbf{0} \sim \mathbf{1 / 4}) \mathbf{R D}^{\mathbf{b}}$ & $\mathbf{( 1 / 4 \sim 1 / 2 )} \mathbf{R D}$ & $\mathbf{( 1 / 2 ~ 3 / 4 ) ~ R D}$ & $\mathbf{( 3 / 4 \sim 1 )} \mathbf{R D}$ \\
\hline 1.5 & 0.40 & 0.28 & 0.19 & 0.13 \\
2 & 0.46 & 0.28 & 0.17 & 0.10 \\
3 & 0.56 & 0.26 & 0.12 & 0.06 \\
\hline
\end{tabular}

${ }^{\mathrm{a}} \alpha$ represents shape parameter controlling root distribution

${ }^{\mathrm{b}} \mathrm{RD}$ represents the normalised rooting depth $(0 \sim 1)$

\section{Drainage coefficient}

A capacity-based algorithm with a single drainage coefficient was used in each soil layer in the simulations of soil water movement in the EU-Rotate_N model. The biggest advantage of such an algorithm is its simplicity, and the values of characteristic soil water content are relatively easier to obtain, compared with the soil hydraulic parameters describing soil water retention and conductivity curves. In this study the drainage coefficient was calculated with Equation 2, and the results appeared to be encouraging, as shown in other previous studies (Doltra and Muñoz, 2010; Soto et al., 2014). However, Equation 2 might not be universally held due to the complexity of the soil, and the EURotate_N model treated the drainage coefficient as an optional model input (Rahn et al., 2010). If possible, the model users should calibrate this parameter to get better results.

The numerical simulations of soil water movement using the Richards' equation are more accurate, and normally involved in complicated numerical schemes such as the finite element method (FEM) and finite difference method (FDM). Recently there was a simplified numerical scheme, named Integrated Richards Equation (IRE) method, proposed and tested in the soil-crop system for water cycle (Yang et al., 2009). This scheme, based on the work by Boone and Wetzel (1996) and Lee and Abriola (1999), applied a simple and explicit FDM approach on each soil layer with a small time step. It has been demonstrated that with a time step of $0.001 \mathrm{~d}$ the IRE method could produce the simulated results as accurately as those from FEM. Since the IRE method employed an algorithm similar with that from the capacity-based method, the procedures for modeling water dynamics in the soil-crop system with the basic flow equation were greatly simplified. Such an approach could be utilized in the EU-Rotate_N model in the future so that the model could be more flexible in using different approaches for the simulations of soil water movement. 


\section{Conclusions}

A simple and effective algorithm has been proposed and tested in this study to simulate soil water movement for the EU-Rotate_N model. The simulated values of soil water content at various depths agreed fairly well with the measurements gathered from two experiments on crops with different rooting depth. Compared with the original model, the modified model with the new algorithm for soil water dynamics has greatly enhanced the accuracy of predicted soil water content. This suggests that the modification of the model was successful, and the model could be used more widely for water management in crop production.

Acknowledgements. The authors wish to acknowledge the financial support from National Natural Science Foundation of China (51379187), National Natural Science Foundation of Zhejiang Province (LY17E090001), and Ningbo Science and Technology Bureau, China (2016C10057).

\section{REFERENCES}

[1] Ahuja, L. R., DeCoursey, D. G., Barnes, B. B., Rojas, K. W. (1993): Characteristics of macropore transport studied with the ARS root zone water quality model. - Transactions of the ASAE 36(2): 369-380.

[2] Allen, R. G., Pereira, L. S., Raes, D., Smith, M. (1998): Crop EvapotranspirationGuidelines for Computing Crop Water Requirements. - FAO, Irrigation and Drainage Paper No. 56. United Nations Food and Agriculture Organization, Rome, Italy.

[3] Boone, A., Wetzel, P. J. (1996): Issues related to low resolution modeling of soil moisture: experience with the PLACE model. - Global and Planetary Change 13: 161181.

[4] Brisson, N., Mary, B., Ripoche, D., Jeuffroy, M. H., Ruget, F. et al. (1998): STICS: a generic model for the simulation of crops and their water nitrogen balances. I. Theory and parameterization applied to wheat and corn. - Agronomie 18: 311-346.

[5] Cannavo, P., Recous, S., Parnaudeau, V., Reau, R. (2008): Modelling N dynamics to assess environmental impacts of cropped soils. - Advances in Agronomy 97: 131-174.

[6] Doltra, J., Muñoz, P. (2010): Simulating nitrate leaching from a fertigated crop rotation in a Mediterranean climate using the EU-Rotate_N and Hydrus-2D models. - Agricultural Water Management 97: 277-285.

[7] Fry, E. L., Manning, P., Power, S. A. (2014): Ecosystem functions are resistant to extreme changes to rainfall regimes in a mesotrophic grassland. - Plant and Soil 381: 351-365.

[8] Greenwood, D. J. (2001): Modelling N-response of field vegetable crops grown under diverse conditions with N_ABLE: a review. - Journal of Plant Nutrition 24: 1799-1815.

[9] Greenwood, D. J., Zhang, K., Hilton, H., Thompson, A. (2010): Opportunities for improving irrigation efficiency with quantitative models, soil water sensors and wireless technology. - Journal of Agricultural Science 148: 1-16.

[10] Guo, R., Nendel, C., Rahn, C., Jiang, C. G., Chen, Q. (2010): Tracking nitrogen losses in a greenhouse crop rotation experiment in North China using the EU-Rotate_N simulation model. - Environmental Pollution 158(6): 2218-2229.

[11] Karandish, F., Šimůnek, J. (2018): A comparison of the HYDRUS (2D/3D) and SALTMED models to investigate the influence of various water-saving irrigation strategies on the maize water footprint. - Agricultural Water Management 213: 809-820.

[12] Kumar, R., Jat. M. K., Shankar, V. (2013): Evaluation of modeling of water ecohydrologic dynamics in soil-root system. - Ecological Modelling 269: 51-60. 
[13] Landl, M., Schnepf, A., Uteau, D., Peth, S., Athmann, M., Kautz, T., Perkons, U., Vereecken, H., Vanderborght, J. (2019): Modeling the impact of biopores on root growth and root water uptake. - Vadose Zone Journal 18: 180196.

[14] Lee, D. H., Abriola, L. M. (1999): Use of the Richards equation in land surface parameterizations. - Journal of Geophysical Research 104: 27519-2.

[15] Mohammad, N., EI-Nesr, A., Alazba, A., Šimunek, J. (2014): HYDRUS simulations of the effects of dual-drip subsurface irrigation and a physical barrier on water movement and solute transport in soils. - Irrigation Science 32(2): 111-125.

[16] Molz, F. J., Remson, L. (1970): Extraction term models of water soil moisture use by transpiring plants. - Water Resources Research 6(5): 1346-1356.

[17] Nash, J. E., Sutcliffe, J. V. (1970): River flow forecasting through conceptual models. Part 1: A discussion of principles. - Journal of Hydrology 10: 282-290.

[18] Nyeko, M. (2015): Hydrologic modelling of data scarce basin with SWAT model: capabilities and limitations. - Water Resources Management 29(1): 81-94.

[19] Pedersen, A., Zhang, K., Thorup-Kristensen, K., Jensen, L. S. (2010): Modelling diverse root density dynamics and deep nitrogen uptake - a simple approach. - Plant and Soil 326: 493-510.

[20] Rahn, C. R., Zhang, K., Lillywhite, R. D., Ramos, C., De Paz, J. M. et al. (2007): Development of a model based decision support system to optimize nitrogen use in horticultural crop rotations across Europe-EU-Rotate_N. - Final Scientific Report QLK52002-01100, Wellesbourne.

[21] Rahn, C. R., Zhang, K., Lillywhite, R. D., Ramos, C., De Paz, J. M. et al. (2010): A European Decision Support System, EU-Rotate_N to predict environment and economic consequences of the management of nitrogen fertilizer in crop rotations. - European Journal of Horticultural Science 75(1): 20-32.

[22] Saxton, K. E., Rawls, W. J. (2006): Soil water characteristic estimate by texture and organic matter for hydrologic solutions. - Soil Science Society of America Journal 70: 1596-1578.

[23] Saxton, K. E., Rawls, W. J., Romberger, J. S., Papendick, R. I. (1986): Estimating generalized soil water characteristics from texture. - Soil Science Society of America Journal 50: 1031-1035.

[24] Shaffer, M. J., Brodahl, M. K. (1998): Rule-based management for simulation in agricultural decision support systems. - Computers and Electronics in Agriculture 21: 135-152.

[25] Šimunek, J., Šejna, M., van Genuchten, M. T. (1999): The HYDRUS-2D Software Package for Simulating Two-Dimensional Movement of Water, Heat, and Multiple Solutes in Variably Saturated Media. Version 2.0. IGWMC-TPS-53. - International Ground Water Modeling Center, Colorado School of Mines, Golden, CO.

[26] Soto, F., Gallardo, M., Giménez, C., Peña-Fleitas, T., Thompson, R. B. (2014): Simulation of tomato growth, water and $\mathrm{N}$ dynamics using the EU-Rotate_N model in Mediterranean greenhouse with drip irrigation and fertigation. - Agricultural Water Management 132: 46-59.

[27] Sun, Y., Hu, K. L., Zhang, K. F., Jiang, L. H., Xu, Y. (2012): Simulation of nitrogen fate for greenhouse cucumber grown under different water and fertilizer management using the EU-Rotate_N model. - Agricultural Water Management 112: 21-32.

[28] Sun, Y., Hu, K. L., Fan, Z. B., Wei, Y. P., Lin, S., Wang, J. G. (2013): Simulating the fate of nitrogen and optimizing water and nitrogen management of greenhouse tomato in North China using the EU-Rotate_N model. - Agricultural Water Management 128: 7284.

[29] Dogan, Y., Togay, N., Togay, Y. (2019): Determining irrigation scheduling and different manure sources of yield and nutrient content on maize (Zea Mays L.) cultivation. Applied Ecology and Environmental Research 17(2): 1559-1570. 
[30] Vereecken, H., Huisman, J. A., Bogena, H., Vanderborght, J., Vrugt, J. A., Hopmans, J. W. (2008): On the value of soil moisture measurements in vadose zone hydrology: a review. - Water Resources Research 44: 1-21.

[31] Wang, H., Gao, J. E., Zhang, S. L., Zhang, M. J., Li, X. H. (2013): Modeling the impact of soil and water conservation on surface and ground water based on the SCS and visual modflow. - Plos One 8(11): e79103.

[32] Willmott, C. J. (1981): On the validation of model. - Physical Geography 2: 184-194.

[33] Yang, D., Zhang, T., Zhang, K., Greenwood, D. J., Hammond, J., White, P. J. (2009): An easily implemented agro-hydrological procedure with dynamic root simulation for water transfer in the crop-soil system: validation and application. - Journal of Hydrology 370: 177-190.

[34] Zhang, K., Greenwood, D. J., White, P. J., Burns, I. G. (2007): A dynamic model for the combined effects of $\mathrm{N}, \mathrm{P}$ and $\mathrm{K}$ fertilizers on yield and mineral composition: description and experimental test. - Plant and Soil 298: 81-98.

[35] Zhang, K., Yang, D., Greenwood, D. J., Rahn, C. R., Thorup-Kristenseen, K. (2009): Development and critical evaluation of a generic 2-D agro-hydrological model (SMCR_N) for the responses of crop yield and nitrogen composition to nitrogen fertilizer. - Agriculture Ecosystems and Environment 132: 160-172.

[36] Zhang, K., Greenwood, D. J., Spracklen, W. P., Rahn, C. R., Hammond, J. P. et al. (2010): A universal agro-hydrological model for water and nitrogen cycles in the soilcrop system SMCR_N: critical update and further validation. - Agricultural Water Management 97: 1411-1422. 